\title{
Una ventana al mestizaje: el matrimonio de los indios en el Arzobispado de México, 1660-1686 ${ }^{1}$
}

\author{
Ana De Zaballa BeAscoecheA \\ Universidad del País Vasco UPV/EHU \\ ana.dezaballa@ehu.eus
}

Recepción: 2 de enero de 2016 / Revisión: 29 de febrero de 2016

Aceptación: 5 de mayo de 2016 / Publicación: Diciembre de 2016

\begin{abstract}
RESUMEN
A pesar de los deseos de la Corona por organizar la sociedad indiana en dos repúblicas separadas, de indios y de españoles, la convivencia de las diferentes calidades se hizo inevitable tanto en las ciudades como en áreas rurales. Analizamos en este trabajo el mestizaje de la población indígena con españoles y castas en el Arzobispado de México durante la visita de Francisco Aguiar y Seijas. Se exploran así mismo, las posibilidades que ofrecen las informaciones de matrimonio para descubrir los vínculos y relaciones sociales entre individuos de diferente calidad.
\end{abstract}

Palabras clave: Matrimonio indígena, mestizaje, informaciones matrimoniales, calidades y relaciones sociales, Arzobispado de México, siglo XVII.

\section{A Window into Miscegenation: Indian Matrimony in the Archbishopric of Mexico, 1660-1686}

\begin{abstract}
Despite the Crown's desires to organize the society of the Indies into two separate Republics -that of the Indians and that of the Spaniards- the cohabitation of the different social levels came to be inevitable in cities as well as in rural areas. In this study we analyze miscegenation between the indigenous peoples, Spaniards and Castes in the Archbishopric of Mexico during the pastoral visit of Francisco Aguiar y Seijas. We also examine the possibilities afforded by marriage particulars, in order to reveal the ties and social relations between individuals of different social levels.
\end{abstract}

Keywords: Indian marriages, Miscegenation, Marriage particulars, Social levels and relations, Archbishopric of Mexico, $17^{\text {th }}$ Century.

SuMARIO: 1. Introducción. 2. Matrimonios mixtos: el mestizaje de la población indígena. 3. Visita y amancebamiento. ¿Presión para el mestizaje? 4. El mestizaje social: relaciones en torno al matrimonio. 5. Migraciones y movilidad. 6. Conclusiones. 7. Referencias bibliográficas.

\footnotetext{
1 Este trabajo es parte del Proyecto de Investigación del Ministerio de Economía y Competitividad con el título "Justicia eclesiástica y conformación de la sociedad en la América española colonial”, HAR2012-35197.
} 


\section{INTRODUCCIÓN}

Dentro de un proyecto más amplio sobre Justicia eclesiástica y conformación de la sociedad en la América Hispana colonial, he trabajado durante un tiempo con fuentes doctrinales y pastorales para acercarme al matrimonio de los indios, relacionando la teología moral y la práctica pastoral con la justicia eclesiástica ${ }^{2}$. Los tratados y manuales para párrocos de indios no nos permiten acceder a la práctica de los tribunales pero nos acercan a la práctica pastoral que era lo que pretendí en un primer análisis ${ }^{3}$. Estos libros dan fe de las soluciones que adoptaron diferentes párrocos de indios en casos concretos, tras consultar diversas autoridades y aplicar el criterio forjado en su experiencia entre los indígenas. Es decir, los instrumentos de pastoral reflejan el sentir de los siglos XVI, XVII y XVIII, que se concreta en la experiencia y la adaptación de la doctrina y normativa a las circunstancias y necesidades específicas de la población. Estas fuentes no son meros tratados de metas ideales en la cristianización de los indios sino que informan sobre la realidad.

En el presente artículo llega ya el momento de contrastar la práctica pastoral con la judicial, para lo cual utilizaré una fuente documental peculiar, las informaciones y diligencias previas al matrimonio. Como es sabido,

Todos cuantos querían casarse necesitaban abrir un juicio ante la autoridad eclesiástica. El varón acudía ante el provisor o su delegado (...), y presentaba una solicitud en que exponía su deseo, compromiso explícito con la fémina y la ausencia de impedimentos. Después, ambos contrayentes presentaban testigos por los cuales pretendían probar su dicho ${ }^{4}$.

Las diligencias matrimoniales son mucho más ricas que los libros parroquiales de registro de matrimonio, pues además del nombre de los contrayentes, sus padres y su lugar de residencia, aportan una interesante información sobre los testigos que les avalan: profesión, lugar de residencia, calidad, etc. Evidentemente no todas las licencias llegaban a hacerse efectivas, pero nos ofrecen información de las relaciones entre grupos bien diversos de la sociedad colonial.

En concreto las fuentes con las que se ha llevado a cabo esta investigación son 145 informaciones y diligencias previas al matrimonio en las que al menos uno de los contrayentes es indio. Proceden prácticamente en su totalidad del Archivo Histórico del Arzobispado de México ${ }^{5}$, y pertenece a un grupo documental especialmente interesante. Se trata de las informaciones matrimoniales que se despacharon en el

2 No podemos olvidar que la doctrina moral de la iglesia es fuente de interpretación jurídica; es decir, forma parte del complejo cuerpo del aspecto doctrinario del derecho canónico. TrASLOSHEROS, 2014, XI-XIV.

3 Zaballa, 2013; Zaballa, 2016.

4 Traslosheros, 2014, p. 134. Por último rendían sus personales declaraciones para dejar fuera de duda el ser libres, sin compromiso alguno y no haber dado voto que les impidiese el matrimonio. De no encontrarse irregularidades el juez eclesiástico competente emitía un auto otorgando la debida licencia.

5 Fondo Episcopal, Sección Secretaría Arzobispal, Diligencias Matrimoniales. Archivo Histórico del Arzobispado de México (en adelante AHAM). Únicamente dos diligencias proceden del Archivo General de la Nación (en adelante AGN); se trata de dos informaciones matrimoniales realizadas en dos pueblos del recorrido y las fechas de la primera visita. 
territorio del Arzobispado de México durante los tres primeros derroteros de la Visita general de Aguiar y Seijas (1683-1686) ${ }^{6}$. El territorio recorrido fue considerable. Durante el primer derrotero, llegó como punto más alejado hasta Tampico que dista de la capital unos $450 \mathrm{Km}$ en línea recta; el segundo recorrido que parte hacia el sur del territorio llegó hasta Tasco a $177 \mathrm{Km}$; y en el tercer derrotero, dirigido hacia el norte, alcanzó Querétaro, a 219 Km de la ciudad de México. En el mapa ${ }^{7}$ se puede apreciar en sus líneas generales dispersión de las poblaciones visitadas y por tanto el extenso territorio que llegó a recorrer.

Por el número que estamos manejando, es evidente que no se trata de una fuente cuantitativa, sino de una fuente de valor representativo de la que pretendo hacer un análisis cualitativo. Las licencias despachadas al paso del obispo por las diferentes parroquias, son como una muestra ${ }^{8}$ del comportamiento de esa población. La selección de esa muestra fue la iniciativa de los contrayentes al paso del obispo por el inmenso territorio visitado. Por esto mismo, no pretendo sacar un promedio de cuál fue el comportamiento, sino comprobar el mestizaje que se produjo durante la visita del prelado por su jurisdicción.

No era habitual que las licencias de matrimonio se guardaran en el fondo episcopal del arzobispado, sino en la parroquia correspondiente, pero el particular modo de ser de Aguiar, su meticulosidad, nos brinda la oportunidad de encontrar reunidas en un solo repositorio las licencias de matrimonio de indios que se concedieron durante la visita de los años 1683-1686 en el arzobispado de México.

Hay que resaltar que estas informaciones matrimoniales aquí recogidas se expidieron en un lapso breve de tiempo, tres años, y por tanto, estamos ante individuos de una misma generación entre quienes coincidirían similares dinámicas sociales.

Por otra parte, esta documentación al ser resultado de una visita general ${ }^{9}$, ofrece ejemplos de todo tipo de poblaciones, desde pueblos y pequeñas doctrinas a ciudades y reales de minas; se encuentran tanto las que tenían como base una ciudad o pueblo prehispánico, como las que surgieron de asentamientos fundados por españoles. La diferente composición y costumbres de estas poblaciones no son obstáculo sino riqueza, pues no aporta el dato de un tipo concreto de ciudad o villa, sino compor-

6 Los recorridos de visita de Aguiar y Seijas pueden encontrarse en el Anexo I de este artículo.

7 Vid. Anexo II donde se ha señalado el territorio visitado con los lugares de los que se tienen diligencias matrimoniales.

8 Si pretendiéramos llegar a un número cuantitativamente relevante de licencias de indios, deberíamos recorrer las parroquias del arzobispado para recabar un número importante en relación con la densidad de la población indígena, algo totalmente imposible.

9 Como se sabe, existían dos tipos de visita: visita general y visita especial dirigida a un tema concreto, como matrimonio, idolatrías o cuentas. En cualquiera de los dos casos la visita se podía dirigir a todo el territorio del obispado o a una sola parroquia. En el caso que nos ocupa se trata de una visita general a todo el territorio jurisdiccional cuyos temas se incluían en el edicto de visita. Los edictos de visita general contenían una serie de elementos comunes que recogían los objetivos de la misma: ...primero, orden, decoro y decencia en todo cuanto tuviera directa relación con la administración de los sacramentos y culto divino; segundo, la supervisión de la vida de la clerecía para que fuera de ‘ejemplo y edificación' a los fieles, así como de la 'vida y costumbres' de la feligresía para que ordenara su conducta a la moral deseada; tercero, la revisión de la administración parroquial y de las personas de Derecho canónico como escuelas, hospitales y cofradías que estuvieren dentro de la jurisdicción del obispo y; cuarto, una declaración más general para la corrección y castigo de los 'vicios y pecados públicos y escandalosos'. TrasLosheros, 2014, pp. 91-92. 
tamientos factibles en todos ellos ${ }^{10}$. Por otra parte lo que une a esas poblaciones diversas es el seguir los mismos procedimientos para llegar al matrimonio. Unidad en la diversidad; lo común canónico que se aplica en la diversidad de situaciones y no solamente urbano-rural, sino en cada pareja, en cada situación específica.

Por último, se trata de una información para la que contamos con una fuente especial de contraste: dos libros de visita del arzobispo Francisco Aguiar y Seijas. E1 primero recoge la visita llevada a cabo entre 1683 a $1685^{11}$, y el segundo la visita al sur del arzobispado entre los años 1686 a $1687^{12}$.

\section{MATRIMONIOS MIXTOS: EL MESTIZAJE DE LA POBLACIÓN INDÍ- GENA}

Pronto se estableció en la legislación indiana la separación entre república de españoles y república de indios ${ }^{13}$. Esta separación legal presente en la Recopilación y en muchos otros documentos oficiales, ha llevado a que durante mucho tiempo la historiografía la diera por supuesto. La separación de repúblicas suponía menor mestizaje tanto biológico como cultural, y llevaba a considerar que los cambios de asimilación cultural por parte de los indios fueron por sometimiento ${ }^{14}$.

Sin embargo, poco a poco van aumentando las investigaciones que demuestran que no fue así. Felipe Castro ${ }^{15}$ nos invita a considerar si los indios de las ciudades no lo eran realmente cuando los encontramos con una cultura mestiza, o si simplemente no eran lo que los historiadores habían decidido que debían ser los indios urbanos. Otros

10 Por supuesto en la visita del obispo Aguiar y Seijas se incluyen las doctrinas bajo jurisdicción de las órdenes religiosas, como puede comprobarse en los libros de Visita: "A los muy reverendos padres guardianes, priores, ministros de doctrina y a nuestros curas beneficiados, sus tenientes, vicarios, jueces eclesiásticos y demás ministros de doctrina de la cordillera y partidos contenidos en esta nuestra carta". AHAM, Libro de Visitas de Francisco Aguiar y Seijas (1683). Libro 10, Anaquel 1 (Versión paleografíada por Sánchez Martínez, pro manuscripto en dicho archivo). Desde ahora lo citaré como Libro de Visitas, la fecha y la página de la versión paleografíada. Libro Visitas, 3 noviembre de 1683, p. 1. Como se sabe, en las doctrinas de indios manejadas por regulares -también las hubo manejadas por seculares- siempre hay un titular que oficia de párroco. Esas doctrinas, en tanto curas párrocos, están sujetas a la ordinaria jurisdicción del obispo. Sólo en cuanto a religiosos se rigen por su disciplina particular. Es decir, los obispos siempre las visitan en su calidad de obispos que visitan las parroquias.

11 Libro de Visitas, 1683.

12 LundBerg, pro manuscripto. Por no estar aún publicado y para homogeneizar la cita con el otro libro de visitas, lo citaré como Libro de Visitas, 1686.

13 LeVAGGi, 2001.

14 La historiografía sobre mestizaje es abundante. Se pueden citar desde los pioneros trabajos de RoSENBLANT, 1954, KonetzKe, 1960 y especialmente Mörner, 1960 y 1974, aún de obligada consulta, hasta el reciente de TWINAM, 2015; contamos con estudios realizados desde la historia social como los de SALINERO, 2005, Castillo Palma, 2000, Premo, 2013, o desde la antropología como los de Gruzinski, 2000, o RoBiCHAUX, 2003 y 2005b. También habría que citar los que se encuadran dentro de la demografía histórica como los de Pérez Toledo - Klein, 1992, Rabell, 1990, que hace una revisión de interesantes trabajos sobre demografía indígena a través de los registros parroquiales desde los años 70; y más reciente, un estudio historiográfico en OLIVERo, 2015. Estos últimos nos han interesado menos, debido a nuestro enfoque cualitativo.

15 CAstro, 2010, pp. 10-12. Felipe Castro cita una interesante bibliografía dedicada a analizar la adaptación de los indios urbanos a las costumbres españolas. 
autores muestran la asimilación del orden judicial castellano. Por ejemplo, Ochoa ${ }^{16}$ estudia la utilización de la justicia colonial por parte de indígenas para defender sus derechos frente al adulterio de la otra parte; y yo, por mi parte, analicé la voluntad de los indios de apropiarse, al servicio de sus intereses, de la cultura, el derecho y privilegios que ofrecía el nuevo orden establecido ${ }^{17}$. Respecto al mestizaje biológico hay autores que afirman que las mezclas étnicas existieron desde los inicios del virreinato ${ }^{18}$.

Debemos separarnos de la imagen excesivamente compartimentada, que viene sugerida por el ideal de las dos repúblicas que debían dividir a la sociedad, una imagen que sigue apareciendo al hablar de las sociedades americanas entre los siglos XVI y XVIII. Como dice Ponce Leiva "si algo caracteriza a las sociedades americanas es, precisamente, su variedad, su complejidad interna, su dinamismo, su capacidad para adaptarse a nuevas situaciones y, en definitiva, su extraordinaria versatilidad" 19 .

El matrimonio entre los diferentes grupos étnicos ${ }^{20}$ ha sido abordado desde diferentes perspectivas, pero no encontramos ningún estudio que tenga como centro de análisis el matrimonio mixto, mestizo, de la población indígena. Así, estudios como los de Gonzalbo ${ }^{21}$, Girardi ${ }^{22}$ o Sheed ${ }^{23}$, nos aseguran el aumento de matrimonios mixtos en la segunda mitad del XVIII favorecido por la expansión económica, por la ruptura de barreras entre barrios de españoles e indios, etc., pero realizan ese análisis desde la república de españoles, comentando el comportamiento de los indios de forma secundaria. Lógicamente en los estudios dedicados a políticas matrimoniales es habitual centrar la investigación en los grupos de élite, tanto de españoles como de nobleza indígena ${ }^{24}$, porque entre ellos se descubren con relativa facilidad las estrategias matrimoniales ${ }^{25}$, difíciles de detectar, en cambio, entre los grupos subalternos, donde en todo caso podrían rastrearse búsquedas de ascenso social o económico ${ }^{26}$.

Quienes, a raíz de sus investigaciones, han analizado el comportamiento matrimonial indígena en Nueva España en el siglo XVII llegan a resultados muy distintos dependiendo de las regiones. Desde la fuerte endogamia encontrada en la Zamora del XVII por Calvo ${ }^{27}$, que llega a estimarla en más del $90 \%{ }^{28}$, hasta el mestizaje masivo

16 Оснон, 2010, pp. 352-353, ofrece una amplia bibliografía para comprobar la imposibilidad de mantener separadas ambas repúblicas en la ciudad de México, y Michoacán.

17 Zaballa, 2011a.

18 Schwaller, 2011, pp. 889-914; Castillo Palma, 2001.

19 PONCE, 2007.

20 El término étnico se refiere tanto a los diferentes grupos indígenas, como a estos, españoles y africanos.

21 GonZalbo, 2000.

22 GHIRARDI, 2007, pp. 120-121.

23 SEED, 1991.

24 Pérez-Rocha, 2000; Rojas, 2011, pp. 437-454; Cruz Pazos - Gil García - Rojas, 2007; Cruz Pazos, 2006; Cruz Pazos, 2005.

25 Gonzalbo, 2000, p. 12.

26 Gonzalbo sugiere que entre los grupos intermedios pudo existir la "política" de evitar el riesgo de la pobreza y, en la medida de lo accesible, ascender en el reconocimiento social. GonZALBO, 2007, pp. 1121-1122.

27 CALvo, 1993, pp. 129-130. En ningún caso se encuentran matrimonios entre indio y española o español e india.

28 Esta conclusión sobre la endogamia en Zamora es similar a la que llega Gonzalbo en su estudio sobre varias parroquias mexicanas en la segunda mitad del XVIII; ella anota que posiblemente no fuera tan alta, sino que el párroco o quizá el contrayente de calidad menor, igualara ambas calidades asimilando con el de mayor prestigio. GonZalbo, 2007, p. 1131. 
del que habla Castillo Palma ${ }^{29}$ para la Cholula de la segunda mitad del XVII y que achaca a la fuerte inmigración provocada por la pujanza económica.

La primera diferencia entre ambos casos es que Zamora ${ }^{30}$ podría calificarse como villa de españoles dentro de un área rural y Cholula como ciudad india. Sin embargo, no parece que ninguno de los dos casos pueda tomarse como prototipo de comportamiento puesto que, en las localidades recorridas por el arzobispo de México, encontramos práctica de matrimonios mixtos tanto en el ámbito urbano como en áreas rurales, tanto en ciudades de origen indígena, como en las de nueva creación.

Cuando inicié este trabajo, no buscaba analizar el mestizaje sino el comportamiento indígena en la elección de cónyuge, y lo primero que saltó a la vista al revisar la muestra seleccionada fue el alto número de matrimonios mixtos. En la base de datos elaborada para este trabajo no se puede hablar de endogamia, sino de variedad, pues de un total de 145 registros, sólo 63 matrimonios $(43,44 \%)$ fueron entre indio e india; el resto, 82 matrimonios (56,55\%), más de la mitad, fueron mixtos. En cuatro de estos matrimonios no se nos indica la calidad de la esposa. ¿Se puede suponer que no era india y que no quiso declarar su calidad? La verdad es que ante la variedad de mezclas indicadas en las informaciones, no hay datos para suponer a qué grupo pudieron pertenecer.

Así, al analizar las informaciones matrimoniales de los indios, advertimos enseguida la presencia de otros grupos étnicos demostrando que, efectivamente, los naturales no formaban un universo rígido. En efecto, los indígenas pertenecían a diferentes grupos sociales, unos pocos de prestigio y otros, algo más numerosos, pertenecientes a niveles inferiores, pero en nuestra muestra la mayoría de los casos, ocupa lugares intermedios cuyos miembros ejercían actividades variadas; desde arrieros con mulas propias a maestros u oficiales artesanos, actividades que fueron compartidas con españoles y castas.

Se registra además una alta variedad de mezclas: castizos, mestizos, mulatos, lobos, chinos y matizaciones como "mulato blanco libre" 31 , "castizo natural", o mestindio. Además, hay que tener en cuenta, como dice Schwaler ${ }^{32}$, que en la documentación de la época, en Nueva España el término "mulato" se utilizaba no sólo para la unión de africano con español, sino también para africano con indio; esto supondría una mayor número de mezclas que se encuentran tanto en ciudades o pueblos, como en Reales de minas. También considero de interés señalar que entre los esclavos se citan, además de negros, algunos mulatos y chinos.

29 Castillo Palma, 2001.

30 Gerhard, 1986, pp. 408-410, califica Zamora como ciudad española fundada a fines del XVI. Poca población española pero con grandes haciendas. En 1649 se contaban 100 vecinos españoles. En 1747 con 1181 familias de no indios. Es decir pocos españoles y muchos mulatos y castas.

31 Castillo Palma, 2001, p. 70. Comenta la autora que cuando eran hijos de africanos a veces los llevaban a bautizar como huérfanos pues al asignarles la calidad el párroco lo juzgaba por la apariencia y en caso de ser mulato a secas, era fácil que pasara a ser mulato blanco.

32 SChWALleR, 2011, p. 889, demuestra con citas de documentos del XVI el uso en las fuentes del término "mulatos" para la mezcla entre africano e india con la misma categoría socio-racial ("within the same socioracial category"). Desafortunadamente para los investigadores, la documentación no nos aporta suficiente información de los individuos que no pertenecen a la elite para determinar su ascendencia étnica específica. 
El mayor número de matrimonios mixtos los requirieron las mujeres indígenas. Los indios solicitaron casarse en 17 ocasiones con mujeres no indias, mientras que las indias realizaron los trámites para licencia matrimonial con otros grupos en 65 ocasiones, lo que supondría el 79,26 de las uniones mixtas.

Cuadro 1: Matrimonios de indios durante tres de los recorridos de visita de Aguiar y Seijas en el arzobispado de México ${ }^{33}$

\begin{tabular}{|l|l|l|l|}
\hline \multicolumn{2}{|l|}{ Indio casado con } & \multicolumn{2}{|l|}{ India casada con } \\
\hline Calidad & $\mathbf{N}^{\mathbf{0}}$ & Calidad & $\mathbf{N}^{\mathbf{0}}$ \\
\hline española: & 5 & español & 17 \\
\hline castiza & 2 & castizo & 8 \\
\hline mestiza: & 2 & mestizo & 24 \\
\hline mulata libre & 1 & mulato libre & 2 \\
\hline mulata esclava & 1 & mulato esclavo & 1 \\
\hline negra esclava & 1 & negro esclavo & \\
\hline Sin calidad & 5 & & $\mathbf{6 5}$ \\
\hline Totales & $\mathbf{1 7}$ & & $\mathbf{6 3}$ \\
\hline & & & $\mathbf{1 7}$ \\
\hline Indio & & india & $\mathbf{6 5}$ \\
\hline indio & & No india & $\mathbf{1 4 5}$ \\
\hline india & & No indio & \\
\hline TOTALES & & & \\
\hline
\end{tabular}

Fuente: informaciones matrimoniales AHAM y AGN (elaboración propia).

Lógicamente eran más abundantes los indios y castas que negros o españoles ${ }^{34}$ pero estos últimos aparecen en un número nada despreciable.

Dentro de la valoración social, los investigadores suelen considerar que en los casos de mezcla de calidades solo se producía ascenso social si uno de ellos era español y se inscribían ambos en el libro de españoles de la parroquia ${ }^{35}$. Es decir, el matrimonio de india con español, y en algunos casos, de indio con española, supondría generalmente un punto de ascenso o valoración social para el otro cónyuge. Sin embargo, no sucede así en la documentación que he manejado. De los cinco casos de indios casados con española, cuatro estaban "en mal estado" (o amancebados, como explicaré), que ya es indicio de lo poco que la parte española podría aportar de prestigio o ascenso social. Sólo en una ocasión la española podía haber elevado al contrayente indio, pero los dos testigos indios que acuden a las informaciones previas

\footnotetext{
33 Para ver la distribución geográfica de esta información, vid Anexo I y II.

34 Entre los contrayentes contamos con 80 indios y 128 indias; 17 españoles y 5 españolas; 24 mestizos y 2 mestizas; 15 mulatos y 2 mulatas...

35 GonZalbo, 2007, pp. 1133-1137.
} 
consideraron difícil que tal matrimonio se llevara a efecto por la casi segura oposición paterna de la novia ${ }^{36}$.

Puede servir de muestra la pareja de la ciudad de Querétaro $^{37}$, que presenta como testigos a dos individuos con una gran diferencia social y económica: un mestizo que firmó y era arriero con mulas propias y un esclavo negro ${ }^{38}$. El mestizo dio fe del indio, y el esclavo negro dio fe de ambos. Este último, dijo conocer a la contrayente desde hacía ocho años, lo que era sorprendente porque ella sólo llevaba cuatro viviendo en Querétaro ${ }^{39}$. Una posible explicación de la presencia de tan singulares testigos, sobre todo para la española, es que ella fuese sirvienta en la casa donde también trabajaba el esclavo y posiblemente el contrayente.

De los diecisiete casos en los que un español y una india solicitan licencia para contraer matrimonio, sólo cuatro se encontraban amancebados. La mayoría de ellos vivían en ciudades relacionadas con los reales de minas, o en localidades estancieras; así por ejemplo los encontramos en Real del Monte, Villa de los Valles, Guasquezaloya, Pachuca ${ }^{40}$ Omitlan, San Pedro Mestitlan, Atotonilco, Xocotitlan e Ixmiquilpan.

De los trece matrimonios no presionados por amancebamiento, en seis ocasiones la contrayente india era viuda. Por los oficios de los testigos sólo en un caso se puede deducir que el contrayente español tenía cierta posición social, pues el testigo español era su criado $^{41}$. Pero en los otros casos no hay indicios de que hubiera habido un ascenso social; así, encontramos un testigo español, primo del contrayente, que es carpintero ${ }^{42}$; o un novio español con oficio de pepenador de mina y en otros la participación de únicamente testigos indios ${ }^{43}$; o sólo testigos mestizos e indios sin datos para poder deducir si eran pobres o con cierta relevancia social.

En realidad las distintas características dentro de los matrimonios con español o española muestran una vez más, que no se puede generalizar. Un matrimonio de este tipo no suponía automáticamente un ascenso; todo dependía de la categoría social del contrayente español, incluso del tipo de ciudad y de la región en la que ésta se ubicaba. Por ello, esta documentación por una parte verifica la práctica del mestizaje entre los indios, y por otra presenta la variación de comportamientos, de características, de unos lugares a otros, lo cual exige otras investigaciones de práctica matrimonial indígena en las diferentes regiones de la Nueva España. La calidad con la que más pretendieron casar las indias fueron los mestizos. En bastantes casos residían en reales de minas, pero se encuentran así mismo numerosos ejemplos en pequeños pueblos o en ciudades como Querétaro.

\footnotetext{
36 AHAM, Fondo episcopal, Secretaría arzobispal, caja 13, exp. 43, ff. 46r.-48r.

37 Gerhard, 1986, pp. 231-232; Somohano, 2006, p. 251.

38 AHAM, Fondo episcopal, Secretaría arzobispal, caja 16, exp. 48, ff.62r-63v. [numeración atribuida]; otro ejemplo similar, en AHAM, Fondo episcopal, Secretaría arzobispal, caja 16, exp. 48, ff.6r-7v.

39 Somohano, 2006, pp. 239-262.

40 Gerhard, 1986, pp. 215-217. Dice que para fines del XVIII Pachuca era considerada ciudad, mientras Atotonilco, Omitlan y Real del Monte eran asentamientos subordinados.

41 AHAM, caja 14, exp. 10, ff. 113r-114r.

42 AHAM, caja 14, exp. 10, ff. 56r-57v.

43 AHAM, caja 14, exp. 10, ff. 44r-45r.
} 


\section{VISITA Y AMANCEBAMIENTO. ¿PRESIÓN PARA EL MESTIZAJE?}

¿Qué influencia pudo tener el hecho de encontrarse con la visita del obispo para elegir pareja y solicitar la información? Como es sabido uno de los objetivos de la visita era corregir y enmendar la moral y religiosidad de los fieles. En la visita iban unidos corregir costumbres, gobernar y hacer justicia formando parte de un mismo proceso pastoral ${ }^{44}$. En el edicto previo remitido a cada parroquia se detallaban los comportamientos que quedaban incluidos en inmoralidad y pecado mortal, de forma que a la llegada del prelado lo "arreglaran" voluntariamente o a través de denuncia ${ }^{45}$.

Por tanto, sí se puede asegurar que la presencia del obispo ayudaba a descubrir algunas irregularidades. Debo reconocer que los casos de situaciones irregulares encontrados en este trabajo no han sido especialmente llamativos. Tenemos que esperar al XVIII para encontrar delitos moralmente graves. Sin embargo, como se ha dicho más arriba, un número considerable de quienes acudieron en el momento de la visita a solicitar su licencia, lo hicieron por encontrarse "en mal estado"46. Con estos términos la documentación se refiere normalmente a los bígamos, amancebados o inces$\operatorname{tuosos}^{47}$, pero por el contexto de nuestra fuente parece claro que alude únicamente al amancebamiento.

Para hacernos una idea de la relevancia que tuvo el amancebamiento en los territorios de la visita de Aguiar y Seijas, podemos acompañarle en su recorrido a través del Libro de visita y analizar sus actuaciones a este respecto, así como las disposiciones que sobre este tema dejó en las diferentes parroquias.

Por una parte, comprobamos que en las visitas realizadas entre 1683 y 1687 resolvió de forma inmediata los casos que le presentaron de parejas amancebadas, sin distinguir de qué calidades eran. Así, junto a la lectura del edicto el obispo exhortaba a los que se encontraban en mal estado a que se casasen. En este tipo de casamientos la conducta habitual de Aguiar fue la de conceder las dispensas necesarias para facilitar el matrimonio ${ }^{48}$. La más habitual fue la dispensa de amonestaciones, obligando únicamente a las que se realizaran el mismo día de la boda, pero hubo otras como la que aplicó a una pareja que tenía impedimento de parentesco y oposición familiar ${ }^{49}$.

Evidentemente la denuncia de amancebados podía continuar una vez finalizada la visita del obispo, por lo que de forma habitual despachó licencias a los beneficiados del lugar para dispensar de amonestaciones a los que se hallaran en dicha situación y poder casarlos con rapidez ${ }^{50}$. De forma excepcional, concedió estas licencias a dos

\footnotetext{
44 Traslosheros, 2014, pp. 33-34.

45 Cruz, 2012, cap. 5, pp. 173-174.

46 Ruz, 2002, pp. 126 y ss.

47 Traslosheros, 2004, pp. 133-159.

48 El primer ejemplo de este comportamiento se encuentra el día 24 de diciembre de 1683. Libro de Visitas, 24-XII-1683, p. 172.

49 Ibídem, 11-IV-1685, pp. 1088-1089. Vid. También AHAM, Fondo episcopal, Secretaría arzobispal, caja 13 , exp. 1, ff. 17r.-19v.

50 Ibídem, 29-XI-1683, p. 116, 10-I-685, p. 666, 11-III_1685, p. 960, 16-III-1685, p. 976, etc.
} 
franciscanos que recorrerían parte del arzobispado como misioneros de la Santa Cruzada $^{51}$.

Si volvemos ahora a los datos que tenemos sobre el comportamiento de los indios respecto al matrimonio, es lógico que durante la visita, entre las licencias matrimoniales ordinarias se encontrase un grupo de feligreses "en mal estado" que deseaban poner remedio a su situación. Así, en nuestra base aparecen 43 parejas en dicha situación. Se puede afirmar que la presencia del obispo era un momento propicio para calibrar el número de concubinarios en esas ciudades pues, fuera de la visita, no era fácil que alguien pidiera licencia de matrimonio por "encontrarse en mal estado", a no ser por delación. Sin embargo, tampoco la visita nos ofrece el total de amancebados, pues el propio obispo sabía que dejaba parejas en situación irregular y no fue raro que mandara que "se le dejase nómina [al párroco] de los que no se habían casado, y se hallaron en mal estado, para que hiciese diligencia de que se apartasen" 52 .

En el ámbito secular el concubinato podía llevar consigo duras penas (destierro y azotes, en caso de reincidencia) ${ }^{53}$. En el libro de visitas no aparecen castigos referidos a estas situaciones. Podría decirse, siguiendo a Jorge Traslosheros ${ }^{54}$, que durante la visita se practicaba una justicia graciosa que no tenía una finalidad punitiva, sino pastoral: la de corregir costumbres y enderezar comportamientos, poner remedio a aquellos amancebados solteros o viudos a los que se insta a contraer matrimonio.

Aunque en algunos casos la presencia del prelado contribuyó indudablemente a transformar una situación irregular en matrimonio mixto, los datos que manejamos no permiten afirmar rotundamente una relación directa entre amancebamiento y mestizaje. Me explicaré.

Por una parte, de las 43 parejas que se encontraban en "mal estado", 28 eran relaciones entre diferentes calidades $(65,11 \%)$, pero seguimos contando con un total de cincuenta y dos matrimonios mixtos sin ningún tipo de apremio conocido. Por otra, 15 de los 63 matrimonios endogámicos $(23,80 \%)$ entre indios, se hallaron amancebados, de manera que, evidentemente, no era un comportamiento sólo propio de parejas $\operatorname{mixtas}^{55}$. Es decir, la visita episcopal influyó indudablemente en los matrimonios mixtos pero sin ella contaríamos también con un alto porcentaje de uniones interraciales sin presión.

51 Ibídem, 3-IV-1685, pp. 1049-1050: "Por la presente damos comisión y facultad, la que de derecho se requiere y es necesaria a los padres fray Pedro de Medina y fray Francisco Ydalgo, misioneros de la Santa Cruzada de Querétaro de la orden de san Francisco y a cada uno insolidum para que durante la misión en que están entendiendo en este arzobispado puedan cada uno insolidum recibir y hacer ante si, las informaciones matrimoniales de libertad y las declaraciones de los contrayentes que hallaren estar en mal estado y fueren nuestros feligreses y súbditos en este nuestro arzobispado, (...) proceder al matrimonio, poniendo por escrito al pie de la información que ha de constar firmada de los testigos de ella que supieren escribir, el auto de la dispensa de vanas, estando en este despacho y facultad, certificando el matrimonio que celebraren con testigos, día, mes y año, diciendo en dicha certificación al cura o ministro, a quienes tocaren los feligreses, asienten la partida de dicho matrimonio y (...) con tal que las informaciones de libertad y declaraciones sean bastantes y valga por el tiempo en que estuvieren dichos padres en la misión de este nuestro arzobispado".

52 Ibídem, 3-V-1684, p. 388.

53 KLuger, 2003, pp. 212-215.

54 Traslosheros, 2014, pp. 33-36.

55 Los que se hallaban en "mal estado" vivían en reales de minas como Tasco (6) o Sultepec (3), pero también en ciudades como Querétaro, San Juan del Río (8-10), Toluca, etc. 
Sí puede afirmarse que las uniones entre indios y españolas fueron propiciadas por la visita, pues cuatro de los cinco casos que tenemos se hallaban "en mal estado". Estas parejas vivían en Querétaro ${ }^{56}$, ciudad populosa y de cierta importancia con elevada proporción de población indígena, suficiente para considerarla en el siglo XVII una ciudad mestiza con convivencia de todos los grupos sociales.

No es este el caso de los matrimonios entre indias y españoles. Aparecen diecisiete casos en nuestra muestra y únicamente cuatro parejas se vieron obligadas, o al menos apremiadas, a casarse por encontrarse en situación irregular. Si analizamos sus lugares de residencia, no encontramos explicación satisfactoria para este tipo de "mezcla". Algunos son vecinos de reales de minas (como Pachuca, Real del Monte u Omitlan), pero otros residían en áreas estancieras, como Ixmiquilpan, Xocotitlan, o incluso en ciudades de gran fuerza indígena como Meztitlan o Villa de los Valles. Es decir, los encontramos en poblaciones muy mestizadas donde era fácil la mezcla racial, pero también en aquellas con mayoría indígena o de castas. Quizá el único elemento común es que en ningún caso eran ciudades populosas e importantes.

\section{EL MESTIZAJE SOCIAL: RELACIONES EN TORNO AL MATRIMONIO}

Aún más interesante que el mestizaje biológico es el mestizaje social, es decir las relaciones entre la posición social o económica de los contrayentes y sus posibles vínculos. Para abordar ese mestizaje nos fijaremos no sólo en los contrayentes sino en los otros actores de las informaciones matrimoniales: los testigos. En efecto, esos pequeños "procesos" de las informaciones que se seguían para confirmar la libertad de los novios y la ausencia de impedimentos ofrecen algunas pistas sobre quienes dan fe de los contrayentes. Estas noticias que amplían la visión de los posibles vínculos sociales o profesionales nos ofrecen datos que podrían servir como indicador del comportamiento de la amplia gama de sectores sociales intermedios, de nivel sencillo, $y$ de la fluidez de las relaciones intergrupales en esos años y en aquellas regiones ${ }^{57}$.

Para utilizar como referentes de este mestizaje social a quienes aparecen dando fe de los futuros esposos, partimos de que testificaron porque conocían bien a quienes pretendían casarse y existía algún tipo de conexión entre ellos; así, las diferentes calidades y profesiones o los lugares de residencia de los testigos nos hablan de la convivencia entre esos grupos de población en la vida cotidiana.

Ahora bien, hay que tener cierta cautela con estos actores porque según los manuales para párrocos de indios ${ }^{58}$, se presentaban en ocasiones testigos falsos o corruptos ${ }^{59}$ que incluso podían no conocer a los contrayentes ${ }^{60}$. Las razones del engaño eran

\footnotetext{
56 Gerhard, 1986, pp. 231-232. Querétaro había contado con población indígena en época prehispánica, pero no se le podría considerar asentamiento urbano. Recibió un número importante de españoles y castas.

57 PONCE, 2011, p. 23.

58 SaÉnZ de la PeÑa, 1642, p. 92; Alva, 1634, f. 16v.; PÉREZ, 1713, p. 133; LeÓN, 1611, p. 113r.

59 Zaballa, 2016.

60 Martínez Araujo, 1690, p. 17. Martínez Araujo que ejerció treinta años como párroco en Michoacán, proponía evitar este vicio utilizando como ayudante para las pesquisas a un feligrés indio que colaborara con el párroco. Vid también, Viseo, 1600, Tabla final, matrimonio (sin foliar).
} 
parecidas a las que movieron a los demás grupos de población: la oposición paterna, y sobre todo, la existencia de algún impedimento que los contrayentes querían eludir. Sin embargo, los engaños no eran tan habituales ni tampoco era fácil conseguir su propósito. Así mismo, algunos párrocos con experiencia alertaron de que por falta de tiempo o por comodidad, los curas de indios utilizaban a veces testigos "fijos", de oficio podríamos decir, que difícilmente podrían dar noticia de los posibles impedimentos. Sin embargo, revisada la base de datos de este trabajo, no nos aparece más que un testigo repetido dos veces en un Real de minas. Es decir, podemos confiar en términos generales en nuestros declarantes.

Como he señalado antes, la información relativa a los testigos aporta datos que amplían el conocimiento del entorno del contexto social, profesional y familiar, así como del lugar de residencia. Este último dato podría arrojar luz si contáramos con la traza y características de las ciudades, pues aún en el XVII en algunas ciudades se mantenían barrios diferenciados. Pero no contamos con planos del siglo XVII para las ciudades recorridas en la visita episcopal, ni siquiera para la capital del virreinato, cuyo primer plano urbano con diferenciación de barrios corresponde al siglo XVIII ${ }^{61}$ cuando ya existía una amplia mezcla racial ${ }^{62}$. En algunas informaciones sí contamos con un indio que vive cerca de la plaza mayor, o en el mismo barrio que otro testigo español, pero no son datos suficientes como para poder llegar a la conclusión de que existía convivencia entre unos y otros.

En los últimos estudios sobre indios urbanos ${ }^{63}$ se insiste en que los indígenas de las ciudades estaban en estrecha relación con españoles, mestizos mulatos, y negros, a pesar de los intentos de la Corona de separar las dos "repúblicas". Como dice Castro,

Esta separación, sin embargo, no tenía mucho sentido en las ciudades. Aun los indios que vivían en los barrios coexistían con el resto de la población de manera cotidiana, y con el tiempo contraían estrechas relaciones de interés, trabajo, amistad y conyugalidad ${ }^{64}$.

El primer ejemplo de esta coexistencia lo tenemos en la variedad de calidades de quienes testifican. De hecho no parece que exista diferencia en el valor testimonial de unos y otros, pues hay informaciones en las que sólo testifican indios, o indios, españoles y mestizos, por ejemplo; mientras en otras lo hacen un español y un mestizo..., y en otras los testigos son mujeres, esclavos... ¿tenía el mismo valor el testimonio del indio que del español?, ¿el del esclavo que el del libre?, ¿el de un mulato que el de un mestizo? Entre estos testigos unidos en su testimonio sobre los contrayentes, encontramos todas las calidades. Ciertamente la relevancia de un testigo dependía tanto del foro en el que se presentaba como del tipo de proceso. En las informaciones matrimoniales de ordinario, y este es el caso de nuestros informes, no existe por

61 Lozano, 2010, pp. 237-350.

62 Sin embargo, es posible que poco a poco logremos conocer esos trazados como nos lo ha mostrado ya Somohano que a través de un mapa de Querétaro del siglo XVIII, localiza la traza urbana del siglo XVII. Somohano, 2006, pp. 239-262.

63 Castro, 2010, p. 12.

64 Ibídem, pp. 12-13. 
medio un asunto de litis. En una información matrimonial la condición esencial es conocer al contrayente, y podría suceder que quien mejor conociera a una persona fuera un esclavo doméstico ${ }^{65}$.

Si contabilizamos las calidades de los testigos, contamos con 62 testigos españoles frente a 55 mestizos, y 176 indios, además de otras mezclas.

La variedad de testigos no se refleja únicamente a través de sus calidades, sino también de su actividad profesional y de su estatus social o económico. Respecto al nivel social, entre los testigos de las 145 solicitudes de licencia contamos con pocos personajes de cierto prestigio social: un tesorero de la Santa Cruzada, un gobernador de comunidad indígena, dueños de haciendas o ranchos, miembros del cabildo indígena o con oficios relacionados con la Iglesia; y también pocos en los niveles más bajos, los sirvientes y esclavos. En cambio se constata la declaración de una gran variedad de personas de niveles intermedios como artesanos -y dentro de ellos quienes se desempeñaban como maestros u oficiales-, arrieros con mulas propias o dueños de pequeñas haciendas, que bien se podían considerar como pequeños empresarios, etc.

Es significativo que en todos los oficios encontremos individuos de diferentes calidades que a menudo quedaban equiparados socialmente. Así, entre los arrieros con mulas propias tenemos siete españoles, seis mestizos, tres indios y un mulato. Es decir el mismo número para mezclas que para españoles. Algo parecido ocurre con oficios menores, como el de los arrieros al servicio de otro para el que contamos con cinco españoles, cinco mestizos, tres indios, tres mulatos y un coyote; en realidad se observa poca diferencia entre unas calidades y otras. Qué pocas veces se tienen en cuenta a estos españoles asalariados que ocupaban los mismos oficios que los indios o castas, o a los naturales que alcanzaban -no por su estirpe, sino por negocio o capacidad- niveles medios bien considerados.

Como muestra de las posibilidades que ofrecen estas fuentes para el análisis de mestizaje social vamos a revisar brevemente tres casos. Comencemos por el de un mestizo y una india, ambos viudos, que pretenden contraer matrimonio. Presentan como testigos a un español, dos indios y tres mestizos ${ }^{66}$. De éstos, el español y un mestizo declaran a favor del contrayente y los otros cuatro, dos indios y dos mestizos, a favor de la contrayente.

Por su actividad profesional, comprobamos que había relaciones entre el español y los mestizos, pues dos de ellos eran arrieros con mulas propias, uno de ellos dedicado al acarreo de pulque, una actividad con capacidad económica reconocida, y el otro mestizo trabajaba para un pulquero. Por otra parte los dos indios que testificaron tenían prestigio social y poder político ya que eran, uno gobernador y otro alcalde del pueblo.

Este informe de matrimonio, además de poner en relación la capacidad económica y el poder político indígena, nos da noticia de los lazos familiares que existen entre los testigos y amplía datos acerca de los contrayentes.

65 Muy diferente es la credibilidad de un testigo cuando hay que declarar por un asunto criminal o por otro tipo de litigio. Sin embargo, algunos, como Renzo Honores o Caroline Cunill opinan que según las regiones, circunstancias y asuntos, se puede encontrar en un proceso importante todo tipo de testigos a pesar de lo que dijera la legislación.

66 AHAM, caja 14, exp. 1, ff. 22r-23v. 
La contrayente parece ser una india principal, ya que el indígena, que en el momento de la información era gobernador del pueblo de indios dijo que se crió en su casa lo que lleva a pensar que pudieron tener algún parentesco. El segundo indio que testificó a su favor era alcalde del pueblo. La testificación de los mestizos nos aporta más luz. Aquél que declaró ser arriero con mulas propias, dijo ser yerno de la contrayente y quien estuvo en los últimos momentos con el primer marido de la contrayente ${ }^{67}$; El yerno mestizo y el testigo español comparten el mismo oficio y posición. La mestiza que testifica era hija de la contrayente. Cabe entonces preguntarse, ¿fue español el primer marido de Ana Verónica? aunque parece raro que no esté indicado en la información matrimonial. Quizá fue también mestizo, como el que ahora solicita la licencia para casarse con ella.

Un segundo ejemplo de interrelación de las diferentes calidades y niveles sociales ${ }^{68}$ lo encontramos en la información para el matrimonio entre un español y una viuda india, sin ningún tipo de apremio (pues no se hallaban en "mal estado"). Él tiene 38 años y es soltero. El contrayente español y los dos únicos testigos, indios, son de Meztitlan ${ }^{69}$, territorio importante en época prehispánica.

Podríamos considerar este segundo caso como modelo de inserción española en el ámbito indígena. Sólo testifican los indios de alto estatus: uno era el gobernador y el otro un cacique que fungía como mayordomo de cofradía; ambos ostentaban el título de Don y el gobernador sabía firmar. El cacique es titulado como indio principal.

Estos dos testigos están relacionados con el contrayente español, pues lo conocen desde que tenía 16 años; bien se puede pensar que a esa edad sus padres emigraron desde Octupa -donde nació el novio- a Meztitlan. De la novia sólo se preocuparon de asegurar que la conocieron casada y vieron enterrar a su marido que era indio. Otro dato que interesa resaltar es que ella declaró mediante intérprete, posiblemente nahua u otomí, lo que hace presuponer que esa inserción del novio español incluía el conocimiento de la lengua indígena.

Nos fijamos, en tercer y último lugar ${ }^{70}$, en el pretendido enlace de una india con mestizo. El contrayente emigró de ciudad de México al Real de Omitlan, donde conoció a su futura esposa. Entre los testigos se cuentan desde el Regidor mayor del Real de Pachuca, que era indio ladino, hasta un simple barretero de la mina (indio) y un mulato libre que trabajaba en una hacienda.

La relación entre los testigos y contrayentes es de dos tipos: laboral y familiar. Por una parte, el regidor mayor da cuenta en su declaración, de la movilidad del contrayente y su "estado civil" informando de que estuvo fuera de la mina tres años y de que no le constaba que hubiera contraído matrimonio en ese tiempo ${ }^{71}$.

Por otra, los otros dos testigos son familia directa de los contrayentes pero con características singulares para nuestro análisis: el indio ladino dijo ser hermano del

\footnotetext{
67 AHAM, caja 14, exp. 1, ff. 22r-23v.: "Y lo vio enterrar en el hospital de San Juan de Dios, pues él mismo lo llevó a curar".

68 AHAM, caja 14, exp. 10, fs 104r-105r.

69 Gerhard, 1986, pp. 188-193.

70 AHAM, Fondo episcopal, Secretaría arzobispal, caja 14, exp. 10, ff. 22r.-23v.

71 "Conoce desde hace doce años al contrayente y le perdió la vista hace tres. No sabe que se haya casado en ese tiempo y antes de que faltara del Real lo conoció soltero libre de matrimonio, etc.”.
} 
contrayente que se confesó mestizo. El mulato libre se dijo tío de la contrayente que, a su vez, aseguró ser de calidad india. Caben dos opciones, el engaño sobre las calidades de los que optan a casarse, o una tradición familiar de uniones mixtas. Schwaller hace referencia a ese tipo de tradiciones dentro de una misma familia en el ámbito novohispano ${ }^{72}$.

He elegido estos tres casos entre muchas variaciones de mestizaje; es decir, ninguno de estos procesos es paradigmático del tipo de uniones. Podríamos elegir ejemplos de situaciones muy dispares, desde casos de extrema pobreza y baja condición social, como el matrimonio que se pretendió entre un negro esclavo, con india, que sólo contaron con mulatos obrajeros como testigos ${ }^{73}$; hasta otros de endogamia indígena, mucho más frecuentes.

\section{MIGRACIONES Y MOVILIDAD}

En la consulta de las informaciones matrimoniales llama la atención, la alta movilidad de los contrayentes en el territorio arzobispal. Algunos autores como Silva Prada $^{74}$ consideran que a pesar de la movilidad indígena y su presencia en los barrios de españoles en la ciudad de México, los indios buscaron la endogamia a la hora de elegir cónyuge (entre 1688-1692). Silva Prada concluye que el contacto físico, la convivencia entre las dos repúblicas, entre indios y españoles en la ciudad, no supuso una mezcla étnica, y por tanto se mantuvo la separación de repúblicas desde el punto de vista cultural. Aunque no he recogido datos de la ciudad de México por no entrar en los tres derroteros de visita, podemos utilizar estas conclusiones para compararlas con los datos que encontramos en los pueblos y villas del territorio visitado.

En efecto, las informaciones permiten conocer los cambios de ciudad porque entre los datos que obligatoriamente debían contener era imprescindible indicar el lugar de nacimiento de los contrayentes, el lugar de residencia del momento de la solicitud y, especialmente, cuánto tiempo llevaba viviendo en su último destino. Todo esto para que el beneficiario pudiera asegurar que no existían impedimentos, pues era relativamente frecuente que los indios intentaran ocultar la bigamia u otro motivo de ilicitud a través del cambio de localidad. Así estas fuentes permiten descubrir flujos poblacionales diversos. Por una parte, se observan migraciones del campo a la ciudad en busca de mejores posibilidades de vida, por ejemplo a Querétaro desde Tequixquiac, desde pequeños pueblos a centros mineros, como Pachuca, Real del Monte, etc.

Pero también se comprueba la migración a los reales de minas desde ciudades como México ${ }^{75}$ o Puebla ${ }^{76}$. Encontramos a un mestizo que emigra de ciudad de México al Real de Omitlan y tras residir allí tres años, solicita licencia para casarse con una india del lugar. Este caso nos ofrece modelo de migraciones sucesivas; en efecto, uno de los testigos resultó ser regidor del real de Pachuca, lugar donde conoció al

72 SCHWALLER, 2011, pp. 889-914.

73 AHAM, Fondo episcopal, Secretaría arzobispal, caja 16, exp. 48, ff. 130r.-132v.

74 Silva Prada, 2001.

75 AHAM, caja 14, exp. 10, ff. 22r-23v.; AHAM, caja 14, exp. 10, ff. 38r.-39v.

76 AHAM, caja 14, exp 10, ff. 40r-41r. 
contrayente hacía trece años, antes de que se mudara a Omitlan. El segundo testigo es su hermano que seguía residiendo en Pachuca, su primer destino, por lo que es fácil que emigrara con él.

Se observan también migraciones de una ciudad a otra, quizá por oportunidades de empleo, como el caso del traslado de Celaya a Querétaro ${ }^{77}$, o de Valladolid a Querétaro, donde el despegue de las manufacturas textiles ${ }^{78}$ pudo atraer a muchos trabajadores. Es el caso de un indio de Valladolid que pretendía casar con española nacida en Querétaro ${ }^{79}$. Los testigos, que residían en Querétaro, eran de condición humilde relacionados con los obrajes.

En este como en otros casos se comprueba que existió el efecto llamada, originado por los lazos familiares o por el lugar de origen; estos lazos se mantuvieron o incluso se reforzaron con la emigración como podemos comprobar, por ejemplo, en el caso en el que el contrayente que sólo llevaba cuatro años en Querétaro, contó con testigos que afirmaron conocerle desde hacía diez y quince años respectivamente; es decir puede deducirse que procedían de la misma ciudad de origen, emigraron juntos y mantuvieron la amistad o relación una vez llegados a su nuevo destino.

Como es lógico también encontramos traslados de residencia entre pueblos cercanos como entre Ixtlahuaca (o Istlaguaca) y Xocotlitan ${ }^{80}$ donde enseguida conocían a los que solicitaban la licencia por la alta movilidad entre estos asentamientos cercanos y de reducido tamaño.

Aunque existen casos en los que es la mujer quien procede de un lugar diferente al de residencia, lo más habitual es que fueran los varones los que tuvieran más movilidad.

\section{CONCLUSIONES}

La visita episcopal ofrece una visión general del comportamiento de los indios con respecto al matrimonio en el territorio del arzobispado recorrido en las tres primeras salidas de la visita general y, por tanto, la posibilidad de contar con una "fotografía social" de esos años (1683-1686). La documentación utilizada está constituida por la totalidad de las informaciones solicitadas en cada localidad por parte de los indios al paso del obispo y no son, por tanto, casos aislados recabados de una base de datos mayor. Es difícil entresacar unos ejemplos más atinados. Aunque el número de casos analizado es pequeño estas informaciones tienen la virtud de proceder de diferentes lugares de la archidiócesis, de forma que ofrecen una visión -o una ventana, recogiendo el título de este artículo- amplia y aplicable a diferentes tipos de ciudades y pueblos. La riqueza de estas fuentes requeriría, sin embargo, un estudio posterior que incluyera las informaciones solicitadas por españoles y castas, y que permitiera una comparativa más amplia para limar y afinar los resultados y comportamientos de la población indígena.

\footnotetext{
77 AHAM, caja 16, exp. 48, ff. 64r.-65v.

78 Urquiola Permisán, 1995.

79 AHAM, caja 16, exp. 48, ff. 6r.-7v.

80 AHAM, caja 16, exp. 23, ff. 86r.-87v., 90r.
} 
La Corona pretendió no sólo separar la población indiana en dos repúblicas, sino también evitar la mezcla de los indios con castas. Sin embargo hemos comprobado que la población indígena practicó el mestizaje con todo tipo de calidades y en poblaciones de circunstancias y características dispares a lo largo del territorio arzobispal. Puede llamar la atención que por ejemplo en Pachuca, ciudad y entorno de convivencia de diversas calidades, de 23 solicitudes de licencia, sólo 8 fueran entre individuos de diferente calidad; sin embargo, en Real del Monte de 17 solicitudes, 10 son de parejas mixtas. Así mismo en Querétaro de 14 diligencias para contraer matrimonio 10 lo solicitaron personas de diferente calidad. También se halla elevado porcentaje de parejas mixtas en los pueblos cercanos a la capital del virreinato. Quiero concluir con esto que aún siendo más fácil el mestizaje en un real de minas, el comportamiento no siempre coincide con la teoría.

Uno de los datos que llama la atención es la diferencia entre matrimonios mixtos solicitados por indios (17) respecto a los que pretendieron las indias (65). Una primera explicación es que fueron también más numerosos los casos de amancebamiento entre indias con persona de otra calidad $(22)^{81}$. Otro motivo podría ser la mayor facilidad de las indias para moverse, a través de los trabajos que realizaban, entre los diferentes grupos de población. Sin embargo, no son razones suficientes. Habrá que esperar al estudio completo de la visita para concluir de forma más segura.

Respecto al posible influjo del paso del obispo en los matrimonios mestizos, hay que confirmar que la visita episcopal propició algunos matrimonios mixtos: aquellas parejas que se encontraban amancebadas. El obispo tenía como objetivo "reformar las costumbres" y entre ellas el amancebamiento y concubinato eran las más comunes. La reforma proponía el matrimonio o la separación de estas parejas.

$\mathrm{Si}$ acudimos a los datos, fueron 28 las solicitudes de parejas mixtas que se encontraban en mal estado por lo que aún quedan 52 solicitudes de matrimonio entre indios y otra calidad. Es decir, en la mayoría de las uniones mestizas no existió ningún apremio ni eclesiástico ni social.

Analizando el tema por grupos, es evidente que el matrimonio entre indio y española fue fruto de la visita, pues cuatro de los cinco casos pretendieron casarse por estar amancebados; no parece que fue un tipo de matrimonio común. Muy diferente es el caso de india con español en el que de 17 diligencias matrimoniales sólo cuatro fueron presionadas por encontrarse en "mal estado". Cuando analicemos las licencias de matrimonio solicitadas en la visita relativa al total de la población, podremos concretar qué tipo de uniones fueron más o menos comunes, y también aceptados socialmente.

Por último, a través de la relación entre contrayentes y testigos, se puede intuir las relaciones laborales y sociales, los lazos familiares que existían entre los diferentes grupos de esta sociedad.

Parece evidente que en estos grupos medios, la calidad no va unida automáticamente a un estatus social. Así, por ejemplo, frente a la consideración de que el matrimonio con españoles suponía un ascenso social para la parte indígena, nuestra muestra lo desmiente. Cuatro de los cinco matrimonios entre indios y españolas, se

\footnotetext{
81 Indios con no indias, únicamente SEIS en mal estado.
} 
debieron al amancebamiento; los posibles enlaces entre españoles con indias, sólo en un caso parece que la parte española tenía posibilidades económicas, tratándose en ese caso de una india de buena condición social, a diferencia de lo que indican otros estudios previos para la ciudad de México. Sí se puede afirmar, en cambio, que los indígenas compartieron con los españoles, como con las demás calidades, variadas actividades profesionales y diferentes situaciones sociales y económicas. Encontramos unidos a estos grupos tanto en los trabajos manuales de las minas, en haciendas, o también en posiciones intermedias como arrieros con mulas propias, o maestros de diferentes oficios. Se encuentran casos en los que el mestizaje tiene tradición familiar, es decir, que es practicado en diferentes generaciones.

Por último, las fuentes utilizadas nos han permitido comprobar la alta movilidad de la población. Se advierten migraciones tanto de indios como de españoles y mezclas entre diferentes regiones del Arzobispado de México; se trata de desplazamientos tanto del campo a la ciudad, como de pequeños pueblos a centros mineros, o incluso de ciudades importantes como México a reales de minas; los motivos no aparecen señalados y únicamente pueden suponerse la búsqueda de mejores situaciones laborales o, en algún caso, evitar la oposición familiar al matrimonio.

\section{REFERENCIAS BIBLIOGRÁFICAS}

Alva, Bartolomé de

1634 Confessionario mayor, y menor en lengua mexicana. Y platicas contra las supresticiones [sic] de idolatria, que el dia de oy an quedado a los naturales desta Nueua Espana, è instrucion de los santos sacramentos \&c Nuevamente compuesto por el bachiller don Bartholome de Alua, beneficiado del partido de Chiapa de Mota. Mexico. Por Francisco Salbago, impressor del Secreto del Santo Officio. Por Pedro de Quiñones.

BERnABEU, Salvador - LANGue, Frédérique (coords.)

2011 Fronteras y sensibilidades en las Américas. Madrid. Ediciones Doce Calles.

Bravo Rubio, Berenise - PÉREz Iturbe, Marco Antonio

2004 "Tiempos y espacios religiosos novohispanos: la visita pastoral de Francisco Aguiar y Seijas, 1683-1684”. En MAYER - TORRE VILlar, Religión, poder y autoridad en la Nueva España. México. Universidad Nacional Autónoma de México, pp. 67-83.

Calvo, Thomas

1993 "Familias y sociedad en Zamora XVI-XIX”. Historia de la familia. México D.F. Universidad Autónoma Metropolitana - Instituto Mora, pp. 126-149.

Castillo Palma, Norma Angélica

2000 "Matrimonios mixtos y cruce de la barrera de color como vías del mestizaje de la población negra y mulata (1674-1796)”. Signos históricos. Iztapalapa, México, no 4, pp. 107-137.

2001 Cholula. Sociedad mestiza en ciudad india. Un análisis de las consecuencias demográficas, económicas y sociales del mestizaje en una sociedad novohispana (16491798). México D.F. Universidad Autónoma Metropolitana de Iztapalapa - Plaza y Valdés, S.A. 
CAstro, Felipe (coord.)

2010 Los indios y las ciudades de Nueva España. México. Universidad Nacional Autónoma de México - Instituto Investigaciones Históricas, Serie Historia Novohispana/84.

Chacón Jiménez, Francisco - Hernández Franco, Juan - García González, Francisco (eds.)

2007 Familia y organización social en Europa y América: siglos XV-XX. Murcia. Universidad de Murcia - Servicio de Publicaciones.

Cruz PAzos, Patricia

2005 "Nobles indígenas y mestizos: el acceso al poder en los pueblos de indios de la Nueva España”. En Gutiérrez Escudero - Laviana Cuetos, Estudios sobre América, siglos XVI-XX. Actas del Congreso Internacional de Historia de América. Sevilla. Asociación Española de Americanistas, pp. 1499-1506.

2006 "Redes familiares y alianzas matrimoniales en la nobleza indígena de Novohispania”. En Sánchez Baena - Provencio Garrigós, El Mediterráneo y América. Actas del XI Congreso de la Asociación Española de Americanistas. Murcia. Editorial Regional de Murcia, pp. 371-376.

Cruz Pazos, Patricia - Gil García, Francisco - Rojas y Gutiérrez de Garandilla, José Luis de

2007 “Soy descendiente de don Juan Istolinque y Guzmán: el cacicazgo de Coyoacán en el siglo XVIII". Relaciones. Estudios de Historia y Sociedad. México, no 109, pp. 5173. En http://www.redalyc.org/articulo.oa?id=13710903

Cruz Peralta, Clemente

2012 Visitas pastorales del arzobispo de México, Francisco Antonio Lorenzana (17671769): entre la disciplina eclesiástica y la reforma de las costumbres. México. Universidad Nacional Autónoma de México. Pro manuscripto. Tesis de Maestría.

GERHARD, Peter

1986 Geografía histórica de la Nueva España 1519-1821. México D.F. Universidad Nacional Autónoma de México.

GHIRARDI, Mónica

2007 "Familias, poderes, instituciones y conflictos: Iglesias, preceptos y transgresiones. La vertiente americana". En CHACÓN JiMÉNEZ - HERNÁNDEZ FrANCO - GARCÍA GONZÁLEZ (eds.), Familia y organización social en Europa y América: siglos XV-XX. Murcia. Universidad de Murcia - Servicio de Publicaciones, pp.109-130.

GonZalbo, Pilar

2000 "La familia novohispana y la ruptura de los modelos". Colonial Latin American Review. New York, vol. 9, $\mathrm{n}^{\mathrm{o}}$ 1, pp. 7-19.

2007 "Afectos e intereses en los matrimonios en la ciudad de México a fines de la colonia". Historia Mexicana. México, nº 4, pp. 1117-1161.

GonzÁLez VAles, Luis E. (coord.)

2003 XIII Congreso del Instituto Internacional de Historia del Derecho Indiano: actas y estudios. San Juan de Puerto Rico, vol. 2, pp. 185-226.

Gutiérrez Escudero, Antonio - Laviana Cuetos, Ma Luisa (eds.)

2005 Estudios sobre América, siglos XVI-XX. Actas del Congreso Internacional de Historia de América. Sevilla. Asociación Española de Americanistas.

GRUZINSKI, Serge

2000 El pensamiento mestizo. Barcelona. Editorial Paidós. 
JALPA, Tomás

2010 "Migrantes y extravagantes. Indios de la periferia en la ciudad de México durante los siglos XVI-XVII”. En CAStro, Los indios y las ciudades de Nueva España. México. Universidad Autónoma de México - Instituto Investigaciones Históricas, Serie Historia Novohispana/84, pp. 79-104.

KLUGER, Viviana

2003 “Existió un derecho de familia indiano?”. En GonzÁLEz Vales (coord.), XIII Congreso del Instituto Internacional de Historia del Derecho Indiano: actas y estudios. San Juan de Puerto Rico, vol. 2, pp. 185-226.

KONETZKe, Richard

1960 "Los mestizos en la legislación colonial". Revista de Estudios Políticos. Madrid, no 112 , pp. 113-148.

LEÓN, Martin de

1611 Camino del cielo en lengua mexicana: con todos los requisitos necessarios para conseguir este fin, co[n] todo lo que vn [Christ]iano deue creer, saber, y obrar, desde el punto que tiene vso de razon, hasta que muere. $\mathrm{Co}[\mathrm{m}]$ puesto, por el P.F. Martin de Leo[n], de la Orde[n] de Predicadores. Dirigido al excelentissimo señor don fray Garcia Guerra de la Orde[n] de n[uest]ro padre S. Domingo, Arçobispo de Mexico, y Virrey desta Nueua España. En Mexico: En la Emprenta de Diego Lopez Daualos. Y a costa de Diego Perez de los Rios.

LeVAGGi, Abelardo

2001 "República de indios y república de españoles en los Reinos de Indias". Revista de Estudios Histórico-jurídicos [online]. Valparaiso, no 23, pp. 419-428. http://dx.doi. org/10.4067/S0716-54552001002300009

Lira González, Andrés - Carrillo Cázares, Alberto - Ferrerira Ascencio, Claudia (eds.) 2013 Derecho, politica y sociedad en Nueva España a la luz del Tercer Concilio Provincial Mexicano (1585). México. El Colegio de Michoacán - El Colegio de México.

LozANO, Teresa

2010 "Las comunidades domésticas de indios de la capital novohispana, siglo XVIII". En CAstro, Los indios y las ciudades de Nueva España. México. Instituto Investigaciones Históricas, UNAM, pp. 237-350.

LUNDBERG, Magnus (ed.)

s.a. Visita al sur del arzobispado de Francisco Aguiar y Seijas 1686-1687. Paleografía y transcripción por Mtra. Berenise Bravo Rubio y Mtro. Marco Antonio Pérez Iturbe. México, pro manuscripto.

Martínez Araujo, Manuel

1690 Manual de los santos sacramentos en el idioma de Michuacan. El bachiller Iuan Martinez de Araujo, primer colegial de el Colegio de S. Ramon Nonnato... y cura proprietario treinta años en los partidos de Punguarehuato, è iglesia parrochial de el archangel S. Miguel de Tlazazalca, y su juez eclesiastico, Mexico: por Doña Maria de Benavides, Viuda de Juan de Ribera at the Empedradillo.

MaYer, Alicia - Torre Villar, Ernesto de la (eds.)

2004 Religión, poder y autoridad en la Nueva España. México. Universidad Nacional Autónoma de México. 
MöRnER, Magnus

1960 La mezcla de razas en la historia de América Latina. Buenos Aires. Paidós.

1974 Estado, razas y cambio social en la Hispanoamérica colonial. México. Secretaría de Educación Pública.

OchOA, Margarita R.

2010 “'Por faltar a sus obligaciones': matrimonio, género y autoridad entre la población indígena de la ciudad de México colonia, siglos XVIII y XIX”. En CASTro, Los indios y las ciudades de Nueva España. México. Universidad Autónoma de México Instituto de Investigaciones Históricas, Serie Historia Novohispana, 84, pp. 352-370.

Olivero Guidobono, Sandra

2015 "Reflexiones conceptuales sobre los estudios históricos de la sociedad iberoamericana. Entre la demografía histórica y la historia de la población. Historia social: la importancia de la familia". Naveg@mérica. Revista electrónica editada por la Asociación Española de Americanistas, $\mathrm{n}^{\circ}$ 15. En http://revistas.um.es/navegamerica.

PÉREZ, Manuel

1713 Farol indiano, y guía de curas de Indios. Por el P.Fr. Manuel Perez, del Orden de N.P.S. Augustin, En Mexico, por Francisco de Rivera Calderon.

PÉREZ-Rocha, Emma - TenA, Rafael

2000 La nobleza indígena del centro de México después de la conquista. México. Instituto Nacional de Antropología e Historia.

PÉrez Toledo, Sonia - Klein, Herbert S.

1992 “La población de la ciudad de Zacatecas en 1857”. Historia Mexicana. México, 42, $\mathrm{n}^{\mathrm{o}}$ 1, pp. 77-102. (Ejemplar dedicado a: Demografía histórica II).

Ponce, Pilar

2007 "Versatilidad social y poderes múltiples en la América colonial". Nuevo Mundo Mundos Nuevos, Coloquios, $\mathrm{n}^{\circ}$ 7. En http://nuevomundo.revues.org/index3231.html

2011 "Por el mucho amor que les he tenido...". Sensibilidades y dinámicas sociales en Quito a mediados del XVII". En BernabeU - LANGUe, Fronteras y sensibilidades en las Américas. Madrid. Ediciones Doce Calles, pp. 21-44.

Premo, Bianca

2013 "Familiar: Thinking beyond Lineage and across Race in Spanish Atlantic Family History". The William and Mary Quarterly. Virginia, vol. 70, $\mathrm{n}^{\mathrm{o}} 2$, pp. 295-316. En http://www.jstor.org/stable/10.5309/willmaryquar.70.2.0295

RABELl, Cecilia

1990 La población novohispana a la luz de los registros parroquiales. México. Universidad Nacional Autónoma de México.

RoBICHAUX, David

2005a“'Identidades cambiantes. 'Indios' y ‘mestizos' en el suroeste de Tlaxcala”. Relaciones. Michoacán, $\mathrm{n}^{\circ} 104$, pp. 59-104.

RoBichaux, David (comp.)

2003 El matrimonio en Mesoamérica ayer y hoy, unas miradas antropológicas. México. Universidad Iberoamericana.

2005b Familia y parentesco en México y Mesoamérica. Unas miradas antropológicas. México. Universidad Iberoamericana.

Rosenblant, Ángel

1954 La población indígena y el mestizaje en América. Buenos Aires. Nova. 
RoJAS y GutiÉRREZ de GARANDILla, José Luis de

2011 "Idas y venidas: los nobles indígenas mesoamericanos antes y después de la Conquista española". Revista Española de Antropología Americana. Madrid, vol. 41, n 2, pp. 437-454.

Ruz, Mario Humberto (coord.)

2002 Memoria eclesial guatemalteca, visitas pastorales. Arzobispado primado de Guatemala. México D.F. Universidad Nacional Autónoma de México - Consejo Nacional de Ciencia y Tecnología.

SAÉNZ DE LA PEÑA, Andrés

1642 Manual de los santos sacramentos, conforme al ritual de Paulo V. : Formado por mandado del ilustrissimo, y excelentissimo seńor D. Juan de Palafox, y Mendoza, obispo de la Puebla de los Angeles, electo arçobispo de Mexico ... Impreso con privilegio en México por Francisco Robledo, Año de 1642 (and the 1691 edition).

SALINERO, Gregorio (comp.)

2005 Mezclado y sospechoso: movilidad e identidades, España y América (siglos XVIXVIII): Coloquio internacional (29-31 de mayo de 2000). Madrid. Casa de Velázquez.

SÁnchez Baena, Juan José - Provencio Garrigós, Lucía

2006 El Mediterráneo y América. Actas del XI Congreso de la Asociación Española de Americanistas. Murcia. Editorial Regional de Murcia.

SCHWALLER, Robert C.

2011 "Mulata, hija de negro y india': Afro-Indigenous mulatos In early Colonial Mexico". Journal of Social History. Virginia, vol. 44, no 3, pp. 889-914.

SEED, Patricia

1991 Amar, honrar y obedecer en el México colonial. México. Alianza.

Silva Herrera, Rocío

2014 "Francisco Aguiar y Seijas, Pastor del rebaño". Cuaderno de Estudios Gallegos. La Coruña, vol. LXI, nº 127, pp. 117-142.

SiLva Prada, Natalia

2001 "Impacto de la migración urbana en el proceso de "separación de repúblicas". El caso de dos parroquias indígenas de la parcialidad de san Juan Tenochtitlán, 1688-1692”. Estudios de Historia Novohispana. México, n 24, pp. 77-109.

SOMOHANO Martínez, Lourdes

2006 "La movilidad poblacional en Tlachco/Querétaro, siglos XVI y principios del XVII". Papeles de Población. México, vol. 12, n 49, pp. 239-262. En http://www.redalyc. org/articulo.oa?id=11204909

Traslosheros, Jorge E.

2004 Iglesia, justicia y sociedad en la Nueva España. La Audiencia Arzobispal de México 1528-1668. México D.F. Porrúa.

2014 Historia judicial eclesiástica de la Nueva España. Materia, Métodos y Razones. México D.F. Biblioteca Porrúa.

TwINAM, Ann

2015 Purchasing whiteness: pardos, mulattos, and the quest for social mobility in the Spanish Indies. Stanford (California). Stanford University Press. 
Urquiola Permisán, José Ignacio

1995 "Manufactura e industria textil en México colonial". América Latina en la Historia Económica. México, vol. 2, nº. 4, pp. 17-27.

VisEO, Juan Bautista

1600 Aduertencias. Para los confessores de los Naturales. Compuestas por el padre fray Ioan Baptista, de la Orden del seraphico padre Sanct Francisco. México, en el convento de Santiago de Tleteloco. Por Pedro Ocharte.

Zaballa, Ana de

2011a "Reflexiones en torno a la recepción del Derecho Eclesiástico por los indígenas de la Nueva España". En Zaballa (ed.), Los indios, el Derecho Canónico y la justicia eclesiástica en la América virreinal. Madrid -Frankfurt. Vervuert Iberoamericana, pp. 45-68.

2013 "La influencia del tercer Concilio Provincial Mexicano en los instrumentos de pastoral. El sacramento del matrimonio". En LiRA GonzÁlez - CARrillo CázARes Ferrerira (eds.), Derecho, política y sociedad en Nueva España a la luz del Tercer Concilio Provincial Mexicano (1585). México. El Colegio de Michoacán - El Colegio de México, pp. 71-90.

2016 "Promises and Deceits: Marriage among Indians in New Spain throughout the 17th and 18th centuries". The Americas: A Quarterly Review of Latin American History. Cambridge University Press, Vol. 73, Issue 01, pp. 59-82.

Zaballa, Ana de (ed.)

2011b Los indios, el Derecho Canónico y la justicia eclesiástica en la América virreinal. Madrid-Frankfurt. Vervuert Iberoamericana.

\section{ANEXO I}

\section{Regiones de las cinco salidas de la visita general de Aguiar y Seijas}

\section{Primer derrotero o cordillera: $1683-1684$ de 3 noviembre de 1683 a junio $1684^{82}$}

La primera salida ${ }^{83}$ la hizo del 3 de noviembre de 1683 al 9 de junio de 1684, en ella recorrió la zona más lejana de la sede episcopal, a saber, la Sierra Baja, la Huasteca, la Custodia de Tampico y la Sierra Alta

\section{Segundo derrotero: 21 de noviembre de 1684 al 13 de junio de 1685}

En aquella ocasión salió por el lado de Tacubaya rumbo al Valle de Toluca, recorrió desde San Jacinto, Tacuba, Malinalco, hasta los reales de minas de Sultepec, Tasco y Zacualpa.

\section{Tercer derrotero: 9 de noviembre de $\mathbf{1 6 8 5}$ al 19 de abril de 1686}

El tercer recorrido comenzó tomando la ruta de Cuautitlán-Tepeji-Querétaro y regreso por Tecozautla e Ixmiquilpan.

\footnotetext{
82 Los derroteros de cada salida de visita los he tomado de SILVA, pp. 123-124.

83 Bravo Rubio - PÉrez Iturbe, 2004, p. 79 ofrecen un mapa detallado del primer derrotero
} 


\section{Cuarto derrotero: del $\mathbf{4}$ de diciembre de $\mathbf{1 6 8 6}$ al 9 de abril de $\mathbf{1 9 8 7}$}

Cuarta salida de su visita pastoral entre el 4 de diciembre de 1686 y el 9 de abril de 1687 por las regiones de Chalco, Valle de las Amilpas, Xochimilco y Coyoacán.

5. El quinto derrotero dio comienzo el 26 de noviembre de 1687 y finalizó el 24 de enero de 1688. Tenía previsto llegar hasta el Puerto de Acapulco, pero no lo logró a causa de su precario estado de salud; de esta manera dio por concluida su visita general.

\section{ANEXO II}

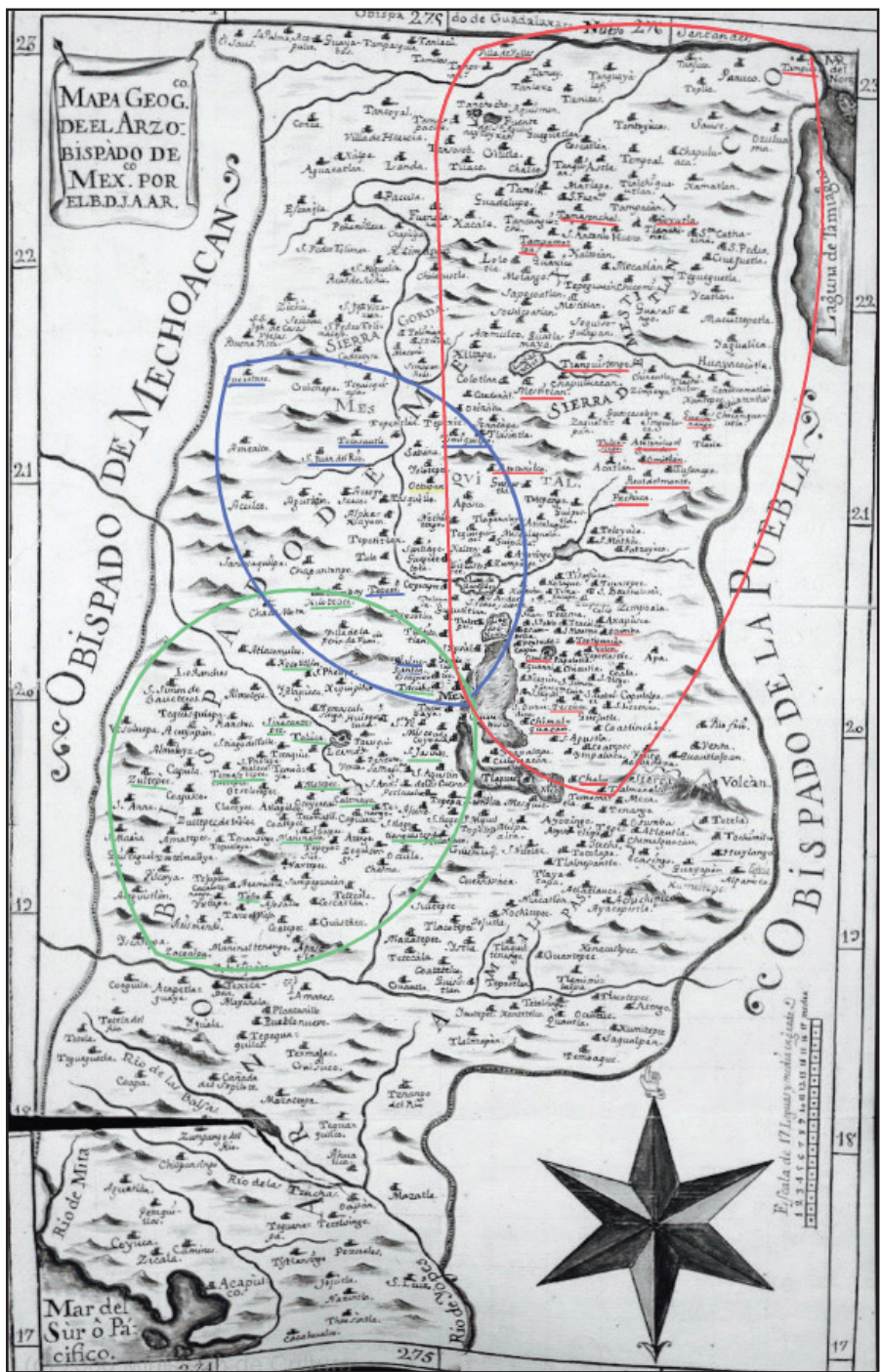

